\title{
How to Manage Migration Flows through a New Model of Development: Inter-ethnic Companies as Good of Order in DRC
}

\author{
Romeo Ciminello ${ }^{1}$
}

\begin{abstract}
Development of global companies must face the risks of diversity and intercultural dialogue, relating to space, time, habits, rites and customs, beliefs and substantiality of the memory of social events. The relational risks are the distinctive "character" of a people: Risks of language, religious, diversity of "values", of "different customs", of perceived education and of various contrasts. Migration flows must be managed in the context of an "Ethical Neo-capitalism". Key points of the project idea: to create development opportunities in the countries of origin with a replicable development model with a multiplier of 1 to 5; to create Cooperatives or Inter-ethnic companies (made up of people of different ethnicities, Europeans and Africans in the diaspora) in the various sectors: credit/agriculture/trade/services/mutuality and infrastructures, proportionally weighted among competent bodies chosen in Italy and in the DRC. The training is divided into two precise moments: a theoretical period in Italy and a period of practical "incubation" in DRC; In Italy: specific courses lasting three to six months and also for trainers, with people already belonging to the sector; the three-month African incubators; Courses in Italy could be financed both by the Italian Development Cooperation and by other possible interested Bodies. Identify in Africa, where and with whom and how, create incubators. During the year of preparation, inter-ethnic companies will have to be able to access a concession (with a privileged system) on which to start the business. Each company will take root in the city with at least 5 thousand inhabitants. The development model will have to be elaborated by points, by sector, by activity, organization, professionals, times and methods to be replicated in the different provinces or territories, where there are large human aggregates.
\end{abstract}

Keywords: Development, Relational risks, Migrations, Ethical -, Neocapitalism, Cooperation

\section{Introduction}

The focus of this paper in the field of economic development is the big problem of migration considered during the history a natural way for people to try to find new places where to survive in better conditions than those abandoned in native countries where normal life is no more possible.

At present there is something changed because of the many barriers put by governments to the possibility of migrants to move freely throughout nations, since market economy and capitalism system consider them as a threat of the wealth and the stability of domestic way of life. Difference is difficult to be accepted in countries that feels invaded by migrant flows and the diversity is refused when people coming from abroad try to shape their own way of life brought from their country of origin. So are refused the different skin color, the different culture and overall is refused the different religion.

In this contest we put three questions. The first concerning why it becomes no more possible for this people to live in one's own homeland; the second is, what are the 
reasons that push them to look for new places where to find better human conditions that could allow them to reshape one's own life and what leads their choice; the third finally, the most important: is it possible to let these people live in their homeland instead of risking their lives to reach so far countries that they did not even imagine to exist before? And could it be possible to help them to remain in their countries building there human conditions of development as well social, political and economic projects? What could be the solution we can suggest as concrete answer to these people whose displace has reached a level of about 258 million in the whole world?

These are tough questions and although we cannot answer properly to all, we want to present how in our organizations 4 metx srl we have tried to find a possible proposal to solve the problem.

Speaking about migrant situations in Italy and Europe we need to explain that there is a lack of understanding on the phenomenon because people cut immigrants only into two categories: refugees and migrants for economic reasons; the first because of the political danger, the second one depending on the economic situation in their country. So if the coming of refugees is tolerated it is quite impossible for the "economic immigrants" reputed illegal and therefore with a strong request to let them be rejected or massively repatriated. Nobody among the most rigid realize that non only refugees, but also immigrants have their lives at risk.

Just to get a very rapid glance on the phenomenon we can observe, according to data published by the last UN International Migration Report 2017, that migrants in the world come mainly from India (with 16 million emigrants from India), from Mexico (12 million), from Russia (11 million) and from China (10 millions). About 5 million migrants are Syrian in origin. The destination countries are the US where the highest number of foreigners is concentrated (47 million). We find Germany and Russia following with 12 million and again Saudi Arabia (10 million) and the United Kingdom ( 9 million). Report shows that Europe is the continent with the highest number of migrants, 76 million in 2015 (were 56 million in year in 2000 ). Inside the countries of North and Western Europe are the most quoted, with a percentage of $13 \%$ for the former and $14 \%$ for the latter, while Italy, although it has more than doubled its share from 2000 to 2015, it remains at a rate of 10\% (5.8 million migrants), this because Italy is considered like the door of the continent trough which to pass to reach most rich countries of northern Europe where to join relatives already settled there. Furthermore the report tells us that migration is a very important phenomenon to take into account because "There are now an estimated 258 million people living in a country other than their country of birth - an increase of 49\% since 2000" (The International Migration Report 2017 - Highlights, a biennial publication of the UN department), outlining that $3.4 \%$ of the world's inhabitants today are international migrants but is to note that this represent only a modest increase from a value of $2.8 \%$ in 2000 . But the number of migrants as a fraction of the population residing in high-income countries on the contrary rose from $9.6 \%$ in 2000 to $14 \%$ in $2017 .{ }^{1}$

1 https://www.un.org/development/desa/publications/international-migration-report-2017.html 


\section{African Migration}

With reference to the Euro-African migration, we consider as an important element the so-called "Rabat Process" held in Rabat (2006), Paris (2008), Dakar (2011), Rome (2014). In these congress are developed collaborations and triennial strategies among the 58 European Countries and Africa Mediterranean, Central and Western countries. These summits discuss the link between migration and development, how to cooperate to fight off crimes related to irregular immigration and in particular the trafficking of human beings and the trafficking of migrants, the management of legal migration, the exigency of international protection as well as the valorization of diasporas and readmissions and voluntary returns.

With regard to the reality of Italian migration policy in international agreements, it is important to highlight the need to look at Europe-Africa relations as a single entity and instead there are many difficulties in sharing migration policies between the various European countries.

We need to outline that Italy has repeatedly taken shared positions, expressed in agreements and programs at European and international level, even if with different orientations and decisions due to the different governments that have alternated in the last twenty years. Other European countries have shared policies, even if not really humanitarian with regard to the African continent and the Mediterranean. Unfortunately, while on the one hand there have been strong impulses from NGOs and private associations, governments have shared their policies in strategic terms that we could classify as a protective order of national interests rather than a humanitarian and host order.

Shared policies are a necessary path to avoid conflicts arising from the need of each state to safeguard its internal stability and therefore it would be enough to harmonize the reception and rejection criteria throughout the European Union. It would be enough to implement, with determination and with the necessary means, the programs agreed in a uniform manner instead of implementing and perhaps only partially, those relating to security and border control.

Italy plays an active role in the "Rabat Process", the above cited forum for political dialogue on migration issues between the EU and the countries of West, Central and Mediterranean Africa. It was born in 2006 on the impetus of Spain, France and Morocco in order to face the challenges posed by migrations along the route between sub-Saharan Africa and the EU, with a shared responsibility and collaboration approach between countries of origin, transit and destination of migratory flows and with a view to mutual interest and development.

The flows from the Sub-Saharan area to the OECD countries are currently the most intense migration process, as indicated in some studies ${ }^{2}$, is destined to remain the most persistent in the coming years.

Migration flows are directly related to both the demographic transition and the gap in the economic development process of the different areas. The Sub-Saharan region doubled

2 Azose et al. (2016), "Probabilistic population projections with migration uncertainty, PNAS, June 2016, 113 no. 23 
its population between 1990 and 2013, recording the fastest growth in the world. According to the UN projection, the demographic transition of the population should end only at the beginning of the next century. Accordingly, estimates the International Monetary Fund, the share of immigrants of Sub-Saharan origin on the total population in OECD countries is expected to increase, rising from 0.4 percent in 2010 to 2.4 percent by $2050^{3}$. In the presence of such persistent economic and demographic asymmetries which cannot be corrected in the short term - a long-term strategy coordinated at European level for the management of a growing migratory phenomenon becomes even more urgent.

Between 2016 and early 2017, the migration and reception strategy for migratory flows at European level was mainly managed through two agreements: 1) the EU-Turkey agreement of March 2016, on the basis of which the number of migrants in Europe through the Western Balkans (mainly from Syria, Iraq and Afghanistan) in 2016 fell to 123 thousand from 764 thousand migrants in $2015^{4}$, and 2) the Italy-Libya memorandum aimed at reducing illegal flows from North Africa, approved by the Malta European Summit in February 2017. Since 2010 Italy has witnessed a tenfold increase in West Africa, especially from Nigeria, Eritrea from Guinea, Ivory Coast and Gambia and other countries for a total of 181,000 people in 2016. According to the Internal Displacement Monitoring Center, the Congolese refugees present in the world today are 493,494, most of whom have found shelter in Kenya, Tanzania and Mozambique, while in the country there are now more than 2.7 million internally displaced persons.

This situation leads us to believe that where conflicts will tend to sharpen, Europe, and Italy above all as a bridgehead, will be natural goals of refuge.

\section{Framework and Reasons of a Project}

Taking into account the problem of migration that clashes with a political vision that increasingly goes towards a return to a totalitarian approach that builds walls instead of building bridges, the atmosphere is not easy. So in a climate of acrimonious reception and the search for rejection opportunities in order to avoid further social problems within European countries and specially Italy, we proposed on july the 11th 2017 the idea of starting to manage migration flows applying an innovative model based on what I call "Ethical neocapitalism", that is to say, instead of repressing migrations, it would be appropriate to prevent them through investment plans in economic terms supported by a more concrete and hitherto unknown humanitarian vision: to prevent the flow of many immigrants heading towards it is necessary to reverse the trend. This could be possible by preventing flows supplying help to the people in their places of origin. In this way they have two choices either to remain in their own country on the basis of concrete development opportunities existing in the area or for expatriated to return to their homeland from abroad: this solution would be very cheaper for them because easy to grasp and concretely organized to respond to a real and actual need to the development

\footnotetext{
3 Gonzalez-Garcia Jetal. (2016), "Sub-Sarahan African Migration Patterns and Spillovers", IMF Spillover Notes 9, November 2016

${ }^{4}$ http:// frontex.europa.eu/news/fewer-migrants- at-eu-borders -in-2016-HWnC1J
} 
strategy of the territories of each African country.

The project is not simple to develop, since as everybody know, there is no trust in novelties because of their present inexistence and their aptitude to upset the traditional existing. For migration problem is harder and we can easily understand the necessity of a change because fear, rejection and walls cannot be the strategy or the right answer to problems nor help to create shared welcoming policies respecting the rights that have brought peace and progress to the integration of the construction of the common European home. So the best way we suggested was a plan that is to create entrepreneurial projects also of cooperative nature and that would be able not only to involve each at least 10 people, but assuming a minimum multiplier of 5 people to occupy, for each company, could develop a natural barrier to immigration quite significant. ${ }^{5}$

It is very important to understand that the development has to answer to many elements non only of economic nature but also cultural, anthropological, social and political one. The environment, where to manage all them, is not a neutral or an abstract place, but is a real space of interaction and its name is Business overall SMB because it is only in the Business and only there that we find the economic premises, the cultural way of life of workers, the anthropological characteristics of people, the social instances and the political aims. That's why we in 4Metx srl proposed this kind of solution involving people coming from any place but forced to find elements of cohabitation and sharing, even if steeped in conflict, competition and mistrust because of their need to reach a better quality of life a better standard of living.

We are certain that development passes only through business, as we have experimented in Italy where immigrant entrepreneurship have become a part of the Italian economic system. We have the report of Unioncamere, that represents the immigrant situation about entrepreneurship in relationship with Italian one. At the end of December $31^{\text {st }} 2013$ there were 6,061,960 enterprises operating in Italy. While individual businesses, equal to $54.2 \%$ of the total, have decreased in number; together with partnerships (18.3\%); corporations $(23.8 \%$ ) and other forms of business (mainly cooperatives and limited liability consortiums) have increased in number. What the reports put in evidence is that there has been a substantial reduction of agricultural, construction and manufacturing enterprises, while the tertiary sector (especially trade, tourism and food), has shown signs of growth. What is interesting to outline is that "even during the years of crisis, and despite major issues like an excessive bureaucracy, difficulties in obtaining bank loans and entering into the Italian market, immigrant entrepreneurs have achieved positive goals with regard to the balance between newly registered enterprises and failed ones."6

It is difficult to understand the real dimension of the phenomenon concerning the immigrant entrepreneurship, if there is not a properly identification of the subject "immigrant-owned enterprises" so Unioncamere in order to verify in a correct manner the question has taken into account some criterion as the place of birth of their owner

${ }^{5}$ This proposal has been discussed with plenipotentiary Minister Dr. Roberto Colaminé DG Cooperazione MAE Head Officer for Help to the development for Subsaharian Africa - at the presence of the president of 4Metx srl and that of the DRC Ambassador in Italy to the Quirinale M. Albert Tshiseleka Felha - Rome 11 th July 2017

${ }^{6}$ IDOS, Rapporto Immigrazione e imprenditorialità 2015, pag. 9 
(in case of sole proprietorships) or of the majority of stakeholders, administrators and share or property holders (in case of other forms of enterprise), thus including in this category a non-negligible number of enterprises started by Italians born abroad and then repatriated, usually from the main countries of destination of the Italian diaspora.

As we can see from the Table 1, businesses led by immigrants have been growing in relationship with that of the Italian born both year on year and on the total.

Table 1: Italy. Companies led by immigrants and born in Italy, absolute values and percentages (2011 - 2013)

\begin{tabular}{lccc} 
& 2011 & 2012 & 2013 \\
\hline Businesses Led by Migrants & & & \\
Number of businesses & 454.029 & 477.519 & 497.080 \\
\hline Balances* & 29.901 & 24.329 & 23.285 \\
\hline Variation\% yoy & & $+5,2$ & $+4,1$ \\
\hline \% on total enterprise & 7,4 & 7,8 & 8,2 \\
\hline Businesses Led by Italian Born & & & \\
Number of businesses & 5.656 .045 & 5.615 .639 & 5.564 .880 \\
\hline Balances* & 20.328 & -5.418 & -10.604 \\
\hline Variation\% yoy & & $-0,7$ & $-0,9$ \\
\hline
\end{tabular}

* Difference between businesses registered and canceled during the year, excluding natural cancellation.

Source: Centro Studi e Ricerche IDOS. Elaborazioni su dati Unioncamere

Just to let readers understand why we have chosen this kind of project we want to outline that we have decided to develop a new model to help people to build comfortable conditions in their home countries thanks to the ability to manage one's own business. From the report we have learned that between the end of 2011 and the end of 2013, 43,000 new "immigrant-owned enterprises" were registered ( $+9.5 \%$ ), for a total of almost half a million $(497,080)$, equal to $8.2 \%$ of the total number of enterprises currently operating in Italy. Furthermore is interesting to note that the most of them are "mainly individual businesses (400,583, equal to $80.6 \%$ of the total) and therefore owned exclusively by immigrants $(94.0 \%)$. It follows that almost one-eighth of all sole proprietorships registered at the end of 2013 is owned by a foreign born worker $(12.2 \%)$. Only in the last year companies (49,507, equal to $10.0 \%$ of the total foreign-owned enterprises) and cooperatives (8,514, equal to $1.7 \%$ ) have increased by $7 \%$ (3 points above the national average of $4.1 \%$ ), and respectively by $13.7 \%$ and $15.9 \%$ compared to the biennium 2011-2013. Partnerships follow with 37,483 units (7.6\%), whereas consortiums (240) and other forms of enterprise (598) are marginal." 7

The numbers the Report put into evidence and that could be relevant to observe for the best comprehension of our decision are that "Lombardy (more than 94,000 enterprises, equal to $19.0 \%$ of the total) and Lazio (around 60,500, 12.2\%) are the top regions, while Rome $(51,000,10.3 \%)$ and Milan $(42,000,8.2 \%)$ are the top provinces. Tuscany $(48,000$, 9.7\%), Emilia Romagna (46,000, 9.2\%) and Veneto (around 42,500, 8.6\%) follow, with more than 40,000 foreign owned enterprises each. At the provincial level the most relevant ones are Turin (around 22,500, 4.5\%), Florence (15,000, 3.1\%), Brescia (12,000,

7 IDOS, Rapporto immigrazione e imprenditorialità 2015 pag. 9 
$2.5 \%$ ) and Naples $(12,000,3.4 \%)$ which is the top ranking province in Southern Italy. Regions with an impact of more than $10 \%$ of the total amount of enterprises are Tuscany, Liguria and Friuli Venetia Giulia (Lombardy, Lazio, and Emilia Romagna follow with almost the same result)." 8

What is worth to note concerning the sector of economic activity is that "Trade (more than 175,000 enterprises, equal to $35.2 \%$ of the total) and construction $(126,000,25.4 \%$ ) are the most relevant sectors, followed by manufacturing $(41,000,8.3 \%)$ tourism and food $(36,000)$. $^{9}$

\section{The Best Place where to Build an Enterprise Cooperative could be the Democratic Republic of the Congo?}

As in many places the problem of immigrants was always discussed without expressing however the will to find a factual solution. After some meetings showing the necessity to let people "stay home" as someone says, instead to invade Europe or Italy, we have made a brainstorming trying to understand what could be a correct proposal to address to the Institutions in order to put a barrier to the fast growing up of the problem.

So on the basis of the cited Report on Immigration and entrepreneurship that has been so clear on the capacity of migrants to build businesses we put the question if it would be possible to think to a new kind of business project based on the idea to build cooperatives that instead to be settled in Europe or Italy could find a place in one of the African countries? We analyzed three eligible African Countries (South Africa, Republic of Sudan, Democratic Republic of Congo) and the result we had was that the best country to choose was the Democratic Republic of the Congo because the characteristic were the best in relationship with all other African countries in terms of territory, population, political situation and low level of development. DRC has an extension of 2 million and 345 thousand square kilometers, with a population currently estimated at less than 100 million and with an average age of around 17 years. The political situation even if now presents some problems, is consolidating around a democratic vision based on free polls and on the economic side DRC has to do a long way to reach an adequate development. On these items we realized that it is a country able to accommodate up to 200 million people in a planned sustainable development perspective, without the existing balances being distorted. That's why after all considerations and my experience of about 20 years of academic teaching with Africans from all countries including Congolese and after 4 years of teaching in Development Economics at the Faculty of Economics and Development of the Catholic University of Congo in Kinshasa, this idea was acknowledged. As a matter of fact the aim was to create inter-ethnic enterprises that could work in an integrated way on a territory rich in opportunities not only physical and animal but also and above all human beings. This idea in its main structure is aimed at ensuring that immigrants, especially Africans in Italy and Europe, can have opportunities for development in their country, or return to their places of origin, with a real

8 IDOS, Rapporto immigrazione e imprenditorialità 2015 pag. 10

9 ibidem 
development project to be implemented.

\section{Characteristics of the Inter-ethnic Enterprise}

The character of the inter-ethnic enterprise must be arranged as a representativeness of socio-economic integration currently difficult to frame. Everyone is aware of the relational difficulty that exists not only between individuals, but also between groups because of differences not only ethnic, but also cultural and socioeconomic. The only way to solve this atavistic problem is to create the business as a good of order, as a system which one can find in human interaction and cooperation in order to allow everyone to express himself in his potential, attitudes and skills. Not to compete competitively, but to compete in an integrative and complementary way. Among the different risks that socio-economic groups have to face in terms of activities and business organization, there are not only technical, political, economic or financial risks, but there are also risks linked to the notion of culture and intercultural negotiation, where culture takes concrete features in theoretical terms related to space, time, habits, rituals and customs, habits and customs, beliefs and substantiality of the memory of social events.

Before proceeding to examine what may be the so-called relational risks deriving from cultural differences, it is important to underline that these differences should not be understood in an absolute sense by constructing stereotypes (Italian = mafia, Muslims $=$ fundamentalists, Americans $=$ bigots, French=colonialists, Scots=miser etc.). Without going further we will try to analyze some peculiarities in order to clarify and categorize the relational risks based on the key elements that make up the distinctive "character" of a people as the language risk, that is the first problem that two persons have to face because of their different languages. But this is not only due to the different idioms, but overall to the notion ideas that their dissimilar experiences has given to certain words. The second risk in the scale of values is the religious risk that is something that is bound to the education and faith. The third is the risk of diversity of values coming from life style deriving from parental models. A fourth risk is that of different customs, coming from diversity of environment, diversity of habitudes and type of family: Another important risk is related to the differences in perceived education and in the sense of civilization coming from three fundamentals: the sense of cleanliness that impose to live in a clean environment and to wash oneself; the sense of accuracy expressed by the need to speak correctly without using bad-mannered words; and last but not the least the sense of dialogue, the ability to accept adverse opinion in a frame of rational critic without totalitarian positions but dialectic confrontation. Finally we cannot fail to note the aesthetic risk given by the inability to evaluate beauty and harmony of things.

In the paragraph I limited myself to listing the various risks deriving from cultural differences. Companies that are able to gain awareness of the presence of these relational risks can proceed to their estimation in order to implement strategies to govern them, in order to turn these risks into opportunities. Attitudes other than respect, understanding and analysis can not only be detrimental to relationships in general, but also, from a business point of view, for the company. The importance of the degree of knowledge of a foreign culture should also be emphasized. There is a lot of difference between a 
simple acquisition of knowledge and the knowledge arising from studies and analysis, and again between this and that deriving from having lived another culture. Having more assimilated and internalized cultures, with reference to risks and opportunities, corresponds to a "competitive advantage". The success factor in the prospect of being able to find a commercial agreement can derive from having fully understood attitudes, desires and internal limits in the culture of the parties, that is having grasped so many cultural nuances. In fact, internalizing multiple cultures changes the global vision and increases the interpretative tools through which we can attribute meaning to the various social contexts.

Finally, I can state, as mentioned above, that in international operations the study of cultural relations and their influence on commercial ones is vital, in order to define and analyze cultural, or relational risks, which unfortunately in most cases they are not taken into consideration. Besides the technical risks we can affirm the existence of relational risks, whose non-consideration could mark the failure for the company. And it is precisely in this context that the idea of Inter-ethnic Enterprise is born.

\section{Key Points of the Project Idea} develops.

Briefly, it follows a summarize of the main points on which the project idea First of all the project idea is to create development opportunities in the countries of origin of African immigrants through a replicable development model with a multiplier of 1 to 5 . The methodology is based on the creation of Cooperatives or Inter-ethnic companies (made up of European and Diaspora Africans) in the various sectors: credit / agriculture / trade / services / mutuality and infrastructure, proportionally weighted. Since the number of jobless in Europe is almost 14 million ${ }^{10}$ we can easily suppose that could be several people willing to settle in Africa to work in their own business. The instrument is a partnership agreement or a partnership, or Temporary Association of Companies between competent bodies chosen in Italy and in the DRC. The training course is divided into two precise moments: a period of theoretical training in Italy and a period of practical "incubation" in DRC in which in Italy there are specific training courses lasting six months and also for trainers, lasting one year with people already belonging to the sector, and who are available to settle in Africa. The period of incubation lasts three months. The courses in Italy and the investment activities in human capital of the three-month African incubators will have to be financed by the EU and the Italian Cooperation and by other possible interested Organizations. In order to reach the goal it is important to identify in Congo (DRC) in the first instance and then in other neighboring countries, where and with whom and how to create incubators (e.g. UCC, Université Loyola du Congo, Université de Mbuji Mayi, ISP Bunia, U.O. Mweka and others). Within a year, while the preparation is taking place, the Inter-ethnic enterprises created must have a concession (with a privileged system) on which to start the business and for this aim it is necessary to create a network of agreements and collaboration with all the Economers of the respective dioceses, both to obtain the

\footnotetext{
10 https://www.truenumbers.it/disoccupazione-europa/
} 
reporting of people, who want to participate in the activities promoted by the incubator, and to obtain information on those who propose themselves on the spot. The development model will have to be elaborated by points, by sector, by activity, organization, professionals, times and methods to be replicated in the different provinces or territories, where there are aggregates.

\section{Cost Estimate for the Project}

The complexity of the project needed to be well evaluated on the side cost and benefit. So we tried to calculate the maximum cost (at market price) for the establishment of a Business cooperative formed by 10 persons in terms of costs of training and for the establishment of the group in the African country. In the Table 2 here under are exposed all costs of development in a transparent manner concerning the different items of education screening single and total cost regarding education and full accommodation and start-up cost in Italy. Then there are calculated the total cost of the incubation period in Africa. Finally there is the calculation of the total cost for all the business created. So dividing the total cost by the number of business it gives the range of the investment level for each of them. If we take into account the possibility to build 1,000 businesses with a total cost of Euro 426,350,000, that means a cost of Euro 426,350,00 for each Business Unit that rises a cost for participant equal to Euro 42,635. We can split the investment in two parts, the first publicly financed and the second part to be paid by each participant. The calculation would present the following numbers: Cost of Euro 426,350 for each business whose first part of 3/4 equal to Euro 319,762.50 would be financed by the EU and the second part of Euro 106,587.50, for $3 / 4$ equal to euro 79,940.63 financed by the Italian Cooperation and the remaining $1 / 4$ of Euro $26,646.88$ by individual participants that being in number of 10 would pay each one Euro 2,664.69. In order to give coherence to the Italian spending we can consider that at present the Italian Government has a total spending for immigration around 4,7 billion euro and since each migrant represents a cost around euro 35 and 45, if we calculate that Euro 79,940.63 is spread over 10 people the single participant has a cost of euro $7,994.06$ that divided by 180 days that is the duration of training in Italy it gives a result of euro 44,41 per day. ${ }^{11}$ Anyway these costs could be reduced up to $49.03 \%$ if a concerted action is organized by Institutions, out of market prices, with savings on classrooms, teachers and accommodation. Here following numbers: 217,310,595.00; $217,310.00 ; 21,731.06 ; 162,982.95 ; 54,327.65 ; 40,745.74 ; 13,581.91 ; 1,358.19 ; 4,074.57$; 22.64 .

\footnotetext{
${ }^{11}$ http://www.eunews.it/2018/06/11/quanto-spende-italia-migranti-unione-europea/106009; http://www.rgs.mef.gov.it/_Documenti/VERSIONE-I/Attivit-i/Contabilit_e_finanza_pubblica/DEF/2018/DEF_2018_Sez_2_-_Analisi_e_Tendenze_della_Finanza_Pubblica.pdf
} 
Table 2: Hypothesis 1 to 1.000 Business (Maximum numbers)

\begin{tabular}{|c|c|c|c|c|c|c|c|}
\hline N. Enterprises & $1.000,00$ & & & Development & & & \\
\hline N. Workers & $10.000,00$ & N. ENTERPRISE & N. Workers & Unit cost & Participant cost & Daily cost & Hourly cost \\
\hline Education'hour per day & 8,00 & 1,00 & 10,00 & $€ 676.100,00$ & $€ 67.610,00$ & $€ 250,41$ & $€ 31,30$ \\
\hline Total hours per enterprise /semester & 960,00 & 10,00 & 100,00 & $€ 451.100,00$ & $€ 45.110,00$ & $€ 167,07$ & $€ 20,88$ \\
\hline Daily cost per single classroom & $€ 50,00$ & 20,00 & 200,00 & $€ 438.600,00$ & $€ 43.860,00$ & $€ 162,44$ & $€ 20,31$ \\
\hline Semester engagement classroom & $6.000,00$ & 30,00 & 300,00 & $€ 434.433,33$ & $€ 43.443,33$ & $€ 160,90$ & $€ 20,11$ \\
\hline N. classroom & $1.000,00$ & 50,00 & 500,00 & $€ 431.100,00$ & $€ 43.110,00$ & $€ 159,67$ & $€ 19,96$ \\
\hline Total classroom cost & $6.000 .000,00$ & 100,00 & $1.000,00$ & $€ 428.600,00$ & $€ 42.860,00$ & $€ 158,74$ & $€ 19,84$ \\
\hline Accomodation daily cost & $€ 25,00$ & 500,00 & $5.000,00$ & $€ 426.600,00$ & $€ 42.660,00$ & $€ 158,00$ & $€ 19,75$ \\
\hline Daly Cost of Meals & $€ 25,00$ & $1.000,00$ & $10.000,00$ & $€ 426.350,00$ & $€ 42.635,00$ & $€ 157,91$ & $€ 19,74$ \\
\hline Total Meals\&accomodation per day & $€ 50,00$ & & & & & & \\
\hline Total Meals\&accomodation per semester & $€ 90.000 .000,00$ & & & & & & \\
\hline N. Tutors & $1.000,00$ & & & & & & \\
\hline Hourly Cost of Tutor & $€ 30,00$ & & & & & & \\
\hline Total Cost of Tutors & $€ 28.800 .000,00$ & & & & & & \\
\hline Cost forfait of Secretariat per semester & $€ 2.000 .000,00$ & & & & & & \\
\hline N. Professor & $1.000,00$ & & & & & & \\
\hline Hourly cost per professor & $€ 100,00$ & & & & & & \\
\hline Total professor Cost per semester & $€ 96.000 .000,00$ & & & & & & \\
\hline \multicolumn{8}{|l|}{ START UP COSTS } \\
\hline Advertising & $€ 100.000,00$ & & & & & & \\
\hline Congress & $€ 50.000,00$ & & & & & & \\
\hline Organization of partnership & $€ 100.000,00$ & & & & & & \\
\hline Total start up costs & $€ 250.000,00$ & & & & & & \\
\hline TOTAL COST IN ITALY & $€ 223.050 .000,00$ & & & & & & \\
\hline \multirow{2}{*}{\multicolumn{8}{|c|}{ TOTALE COSTS OF D.R. CONGO INCUBATORS }} \\
\hline & & & & & & & \\
\hline University accomodation costs per quarter & $€ 27.000 .000,00$ & & & & & & \\
\hline Professor/tutor cost per quarter & $€ 4.800 .000,00$ & & & & & & \\
\hline Cost of Coopec start up & $€ 60.000 .000,00$ & & & & & & \\
\hline N. of concessions requested & $1.000,00$ & & & & & & \\
\hline Cost per hectare of each concession & $€ 230,00$ & & & & & & \\
\hline N. Hectares per each concession & 50,00 & & & & & & \\
\hline Total cost of concessions per enterprise & $€ 11.500 .000,00$ & & & & & & \\
\hline Total costs for initial equipment & $€ 100.000 .000,00$ & & & & & & \\
\hline TOTAL COST IN R.D. CONGO & $€ 203.300 .000,00$ & & & & & & \\
\hline & & & & & & & \\
\hline TOTAL COST OF THE PROJECT FOR ALL ENTERPRISES & $€ 426.350 .000,00$ & & & & & & \\
\hline Total cost of single enterprise & $€ 426.350,00$ & & & & & & \\
\hline Cost per single participant & $€ 42.635,00$ & & & & & & \\
\hline N. days 1 semester +1 quarter & 270,00 & & & & & & \\
\hline Daily Cost per person & $€ 157,91$ & & & & & & \\
\hline Hourly Cost per person & $€ 19,74$ & & & & & & \\
\hline
\end{tabular}

\section{Organization of Enterprises as a New Model of Development}

The step towards the building of the project involves the formation of two different partnership the first in Italy and the second one in Congo R.D. as first step. The second step concerns the groundwork of activities and the planning of actions regarding the aims of each partner, the availability and means of each partner looking at the funding from E.U and Italian cooperation and other partners or interested entities (as associations, or Ong) that could help participant to finance their individual quota. The final step concerns the undertakings to enter in the project model to be replicated in every city in the different provinces of DRC that has at least 5 thousand inhabitants. The model is based on a development of activities based first of all on the engine of credit supplied by a credit cooperative, than the sector of agriculture including a lot of economic activities relating to assessment of the territory; planning of cultures; cultivation of food plants (horticulture); fruit plants (fruit-growing); officinal plants (pharmaceutical and herbal medicine); aromatic plants (kitchen); ornamental plants (floriculture); seed plants (reproduction); nursery (pepinière); mulberry plants (sericulture). We can say that agriculture is important if we mean cultivation as a summary of all process of work that is from sowing to the collection of selection conservation and distribution of seeds. Then there is the agricultural instrumentation and 
uses; agricultural machinery and mechanical support; fertilization and organoleptic properties. Furthermore there is the important sector of breeding: bovine; pig; ovine / caprine; equine; rabbits; beekeeping; snails; silkworms; earthworm culture; poultry and birds (pigeons, turtledoves, pheasants, quails, etc.); antelopes. Other interesting development of works considers processing and conservation of: meat; leather; agribusiness; wood (furniture and construction; eggs and derivatives; preserves and juices. Other possible development are in commerce, trade and marketing: storage of goods and foodstuffs; cold chain; purchasing centers; sales offices. In addition, a service can be activated in the commercial distribution chain: wholesaler; representative; retailer. On the side of services can be developed: water and power supply; viability; building and maintenance; transport; safety; health insurance; mutual insurance.

\section{Conclusion}

Even if the availability of space in this book does not allow to deepen the topic, I hope to have given an idea of what can be made in order to promote development, not only for African people, but also for European. I ask everybody who wants to engage in this kind of project in which the integration of cultures comes before any other opportunity, be it economic or political, because it promotes man and his potential in respect of his rights, his autonomy and his freedom, to do his utmost. I hope that Institutions will be touched and will engage themselves to solve this problem discussing the project in order to promote it or to make it better for the future generations in a vision of a new economy of development really sustainable.

\section{References}

United Nation, Department of Economic and Social Affair Population Division International Migration Report 2017 United nations New York 2017

Centro Studi IDOS, Rapporto Immigrazione e Imprenditoria, Edizioni IDOS , Imprinting srl, Roma Giugno 2014 -ISBN 9788864800509

Calzaroni M., Rizzi R. (2008) L'integrazione straniera nel tessuto economico: fonti attuali e prospettive, in Atti del Convegno "la presenza straniera in Italia: l'accertamento e le analisi", Roma, 15-16 dicembre 2005.

Cassani B., Giudici C., Rizzi R., Immigrant entrepreneurship through the economic crisis in Italy, in Società Italiana di Statistica, "Atti della XLVI Riunione Scientifica” CLEUP, Padova, 2012 p. 78.

Lavorare in aziende cooperative a Reggio Emilia. Relazioni multiculturali, climi lavorativi nei modelli di integrazione, ricerca a cura di D. Giovannini, L. Vezzali e S. Campani, Università di Modena e Reggio Emilia, F. Aravisi, "Cooperative, stranieri a rischio perché troppo ricattabili", Corriere della Sera, 7 novembre 2013.

Ambrosini M., Richiesti e respinti, ed. Il Saggiatore Milano 2010.

Ambrosini M., Sociologia delle migrazioni, ed. Il Mulino, Bologna 2011.

Deakins D. Entrepreneurship and small firms, ed. Graw Hill, Londra 1999.

Chiesi, A.M., e De Luca, D., Imprenditori immigrati in Italia: il problema della dimensione e dell'efficienza", in Quaderni di Sociologia 2012 LVI (58); 41-65.

Engelen E., “'Breaking in' and 'Breaking out': A Weberian Approach to Entrepreneurial Opportunities”, Journal of Ethnic and Migration Studies, 2001, 27 (2): 203-223

HettlageR., "From Ethnic Business to Hybrid Entrepreneurs: 35 Years of Research on Self-Employed Immigrants", Kalaidos Fachhochschule Schweiz, Working Paper, n. 032008

Piguet E., Les Migrations créatrices, Harmatta, Paris 1999. 
Pecoud A., "Les enjeux de l'entreprenariat immigré », in Revue de l'Intégration et de la Migration Internationale, 6 (3/4), $2005: 377-403$

Centro Studi IDOS, Dossier Statistico Immigrazione 2015, Edizioni IDOS , Imprinting srl, Roma, Ottobre 2015 -ISBN 9788864800349

Azose et al. (2016), "Probabilistic population projections with migration uncertainty, PNAS, June 2016, 113 no. 23

Gonzalez-Garcia Jetal. (2016), "Sub-Sarahan African Migration Patterns and Spillovers", IMF Spillover Notes 9, November 2016.

\section{Web References}

http://frontex.europa.eu/news/fewer-migrants-at-eu-borders-in-2016-HWnC1J

https://www.truenumbers.it/disoccupazione-europa/

http://www.eunews.it/2018/06/11/quanto-spende-italia-migranti-unione-europea/106009/

http://www.rgs.mef.gov.it/Documenti/VERSIONE-I/Attivit--

i/Contabilit_e_finanza_pubblica/DEF/2018/DEF_2018_-Sez_2_-

_Analisi_e_Tendenze_della_Finanza_Pubblica.pdf/

http://www.un.org/en/development/desa/population/migration/index.shtml

https://www.un.org/development/desa/publications/international-migration-report-2017.html

http://www.stranieriinitalia.it/news/coop2ago2005.htm

http:/ / www.boorea.it/Sezione.jsp?titolo $=1 \% 20$ lavoratori $\% 20$ immigrati $\% 20 \mathrm{e} \% 20 \mathrm{le} \% 20$ cooperative. $\% 20$ Una $\% 20$ ricerca $\% 20$ con $\% 201$ 'Universita $\% 20$ di $\% 20$ Mdena $\% 20 \mathrm{e} \% 20$ Reggio\&idSezione $=263$ 